Open Access

\title{
Association between the GRM7 rs3792452 polymorphism and attention deficit hyperacitiveity disorder in a Korean sample
}

Subin Park', Sun-Woo Jung ${ }^{1}$, Boong-Nyun Kim ${ }^{1 *}$, Soo-Churl Cho ${ }^{1}$, Min-Sup Shin ${ }^{1}$, Jae-Won Kim ${ }^{1}$, Hee Jeong Yoo ${ }^{2}$, Dae-Yeon Cho ${ }^{3}$, Un-Sun Chung ${ }^{4}$, Jung-Woo Son ${ }^{5}$ and Hyo-Won Kim ${ }^{6}$

\begin{abstract}
Background: The purpose of this study was to investigate the association between the ionotropic and glutamate receptors, N-methyl D-asparate $2 \mathrm{~A}$ (GRIN2A) and 2B (GRIN2B), and the metabotropic glutamate receptor mGluR7 (GRM7) gene polymorphisms and attention-deficit hyperactivity disorder (ADHD) in Korean population.

Methods: We conducted a case-control analysis of 202 ADHD subjects and 159 controls, performed a transmission disequilibrium test (TDT) on 149 trios, and compared scores from the continuous performance test (CPT), the Children's Depression Inventory (CDI), and the State-Trait Anxiety Inventory for Children (STAIC) according to the genotype of the glutamate receptor genes.

Results: There were no significant differences in the genotype or allele frequencies of the GRIN2A rs8049651, GRIN2B rs2284411, or GRM7 rs37952452 polymorphisms between the ADHD and control groups. For 148 ADHD trios, the TDT analysis also showed no preferential transmission of the GRIN2A rs8049651 or GRIN2B rs2284411 polymorphisms. However, the TDT analysis of the GRM7 rs3792452 polymorphism showed biased transmission of the $G$ allele $(X 2=4.67, p=0.031$ ). In the ADHD probands, the subjects with $G G$ genotype in the GRM7 rs37952452 polymorphism had higher mean T-scores for omission errors on the CPT than did those with the GA or AA genotype ( $t=3.38, p=0.001$ ). In addition, the ADHD subjects who were homozygous for the $G$ allele in the GRM7 rs37952452 polymorphism had higher STAIC-T $(t=5.52, p<0.001)$ and STAIC-S $(t=2.74, p=0.007)$ scores than did those with the GA or AA genotype.
\end{abstract}

Conclusions: These results provide preliminary evidence of an association between the GRM7 rs37952452 polymorphism and selective attention deficit and anxiety found within the Korean ADHD population.

Keywords: Attention-deficit/hyperactivity disorder (ADHD), Transmission disequilibrium test, Continuous performance test, Genetic polymorphism, Anxiety

\section{Background}

Attention-deficit hyperactivity disorder (ADHD) is a disorder primarily characterized by inattention, impulsivity, and hyperactivity and has a worldwide prevalence of 5.3\% [1]. It has an estimated heritability of approximately $76 \%$ and is thought to be a complex, polygenic disorder [2].

Although the exact etiology of ADHD is unknown, one theory posits that the dysregulation of neurotransmitter

\footnotetext{
* Correspondence: kbn1@snu.ac.kr

${ }^{1}$ Department of Child and Adolescent Psychiatry, Seoul National University Hospital, Seoul, Korea

Full list of author information is available at the end of the article
}

systems underlies the pathogenesis and associated cognitive and locomotor deficits of this disorder [1]. Previous pharmacological and animal knockout studies have strongly implicated dopaminergic and noradrenergic systems in ADHD [3-5]. In addition, similar types of studies support involvement of the glutamatergic system in behavioral models related to ADHD. Magnetic resonance spectroscopy showed an increased glutamatergic tone in the frontal and striatal brains of subjects with ADHD [6-8] that normalized with stimulants and atmoxetine [9]. Dysregulated expression of glutamatergic pathway genes has been observed in spontaneously hypertensive rat models $[10,11]$.

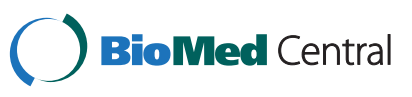


Increased concentrations of glutamate were also reported in the neurometabolism of ADHD brains, which is consistent with altered glutamate transmission in ADHD [8].

Glutamate is the primary excitatory neurotransmitter in the brain and is found as a neurotransmitter in approximately $60 \%$ of brain neurons, including almost all cortical pyramidal neurons. Glutamate receptors are responsible for the majority of excitatory synaptic transmissions and plasticity in the central nervous system [12]. Because of this central role in neuronal communication and synaptogenesis, glutamate receptors control several cellular and cognitive processes [13]. Glutamate mediates its effects on the central nervous system via both ionotropic and metabotropic receptors. Ionotropic glutamate receptors are subdivided into three categories based on their respective agonists, namely, a-amino-3hydroxy-5-methyl-4-isoxazole propionic acid, kainate or $\mathrm{N}$-methyl-D -aspartate (NMDA). The classic learning and memory receptors, NMDA receptors (NMDARs), are composed of heteromeric complexes containing an obligatory NR1 (GRIN1) subunit, plus an additional NR2 (GRIN2A-D) or NR3 (GRIN3A, B) subunit (Riedel et al. 2003). The metabotropic glutamate receptors (mGluRs), which are G-protein-coupled receptors, are divided into 3 groups on the basis of sequence homology, putative signal transduction mechanisms, and pharmacologic properties [14,15]. The mGluRs in group I are mGluRs 1 and 5; mGluRs 2 and 3 in group II; and mGluRs 4, 6, 7, and 8 in group III. Group II and group III mGluRs are linked to inhibition of the cyclic AMP cascade but differ in their agonist selectivities. Among these mGluRs, mGluR7 is the most highly conserved mGluR subtype across mammalian species [16].

The NMDAR subunits GRIN2A and GRIN2B play essential roles in memory and learning by regulating key aspects of synaptic plasticity (Kutsuwada et al. 1996; Tang et al. 1999). Mice lacking the NMDAR 2A subunit gene GluRe1 (the mouse homolog of the GRIN2A gene in humans) show increased spontaneous locomotor activity in novel environments, impaired latent learning associated with selective attention [17] and deficits in spatial learning [18]. Overexpression of the NMDAR 2B subunit gene GluRe2 (the mouse homolog of the GRIN2B gene in humans) in the forebrain of mice enhanced hippocampal long-term potentiation, spatial learning and memory and improved learning processes involved in fear extinction [19]. Knockout studies of GluRe2 indicate that this subunit is essential for development, neuronal patterning and synaptic transmission in the CA1 region of hippocampal slices [20]. The GRIN2A exon 5 polymorphism was associated with ADHD in two of three family studies [21-23], and GRIN2B SNPs showed significantly biased transmission, with the strongest evidence of association found for rs2284411 in ADHD families [24].
It is of particular interest that the metabotropic glutamate receptor mGluR7 (GRM7) gene is widely expressed in the cerebral cortex, hippocampus, and cerebellum, and studies have established a relationship between structural differences in these areas and ADHD [25,26]. Furthermore, mGluR7 has putative roles in anxiety, fear responses, and working memory [27-30]. Deficits in working memory have been identified as potential core factors in the development of ADHD, and anxiety is also a frequently associated condition. Although relational studies investigating GRM genes that encode mGluR have reported mixed results, a Genome-Wide Association Study examining the methylphenidate response in children with ADHD found an association with an SNP in GRM7 gene (rs3792452) [31].

The above-mentioned evidence suggests that GRIN2A, GRIN2B, and GRM7 represent candidate genes for ADHD or certain phenotypes of ADHD. However, the few association studies investigating glutamate genes have yielded mixed results, and all of the above-mentioned studies were conducted on Caucasian populations. Therefore, the purpose of this study was to examine the relationship between ADHD and three glutamate genes: SNPs-GRIN2A exon 5 gene SNP (rs8049651), GRIN2B gene SNP (rs2284411), and GRM7 gene SNP (rs3792452). We conducted a case-control and family-based association study and compared the results of a continuous performance test and clinical scale according to each genotype. We selected these three glutamate genes because of their historical prevalence in the literature examining glutamate genes in relation to ADHD.

\section{Methods}

\section{Subjects}

We recruited children with ADHD from three child psychiatric clinics at university hospitals in Korea: Seoul National, Kyungpook National, and Chungbuk National Hospitals. Inclusion criteria were (1) diagnosis of ADHD according to the Diagnostic and Statistical Manual of Mental Disorders, 4th edition, text revision (DSM-IV-TR) [32]; (2) a score above the 90th percentile on the ADHD Rating Scale-IV (ARS) [33]; (3) a T-score greater than 60 on the Attention Problems subscale of the Child Behavior Checklist (CBCL) [34]; and (4) an intelligent quotient (IQ) higher than 71 on the Korean Educational Developmental Institute's Wechsler Intelligence Scale for Children (KEDI-WISC) [35].

In addition, we recruited control group subjects from five different administrative regions in Korea: Seoul, Seongnam, Incheon, Ulsan, and Yeoncheon. The children were selected for the control group based on the following criteria: (1) did not meet the criteria for a DSM-IV diagnosis of ADHD according to the Korean version of the Diagnostic Interview Schedule for Children Version-IV (DISC-IV) [36,37]; (2) 
scored below the 90th percentile on the ARS; (3) had a T-score of less than 60 on the Attention Problem subscale of the CBCL; and (4) had an IQ score higher than 71 on the KEDI-WISC.

Subjects were excluded from the study if they had one or more of the following: (1) past and/or current history of any neurological disorder, including a seizure disorder or brain damage; and (2) presence of a comorbid psychosis, Tourette's, bipolar, communication, learning, or pervasive developmental disorder. In the ADHD subjects, ADHD and comorbid disorders were diagnosed using the Korean version of the Kiddle Schedule for Affective Disorders and Schizophrenia-Present and Lifetime Version [38,39].

The study was approved by the institutional review board (IRB) for human subjects at the Seoul National University Hospital and other hospitals. Parents/guardians provided written informed consent, and the children or adolescents provided verbal assent regarding participation in this study.

\section{Neuropsychological assessments}

We used a computerized continuous performance test (CPT) [40] to measure the neuropsychological functions of the ADHD children and controls. The Korean version of the CPT was standardized, and its validity and reliability have been well-established [41]. The four variables recorded included: (1) omission errors (failure to respond to the target), commonly interpreted as a measure of inattention; (2) commission errors (responding inappropriately to the non-target), commonly interpreted as a measure of impulsivity; (3) response times for correct responses to the target, interpreted as a measure of information processing and motor response speed; and (4) the standard deviation of the response times for correct responses to the target (response time variability), which is interpreted as a measure of variability or consistency of attention.

\section{ADHD children's emotional symptoms}

ADHD children's emotional symptoms were measured using the Korean versions of the Children's Depression Inventory (CDI) and the State-Trait Anxiety Inventory for Children (STAIC). The CDI consists of 27 self-report questions along a Likert scale ranging from 0 (not present) to 2 (present and marked), and the total scores on the CDI can range from 0 to $54[42,43]$. The subdomains on the CDI include negative mood, interpersonal problems, negative self-esteem, ineffectiveness, and anhedonia. A total score of 29 is considered the cutoff point for severe depressive symptoms in the Korean version [43]. The STAIC consists of two 20-item scales that measure anxiety level in children $[44,45]$. One scale is the State-Anxiety Inventory for Children (STAIC-S), which asks the subjects to describe how they feel at the present time and how their anxiety increases in response to situational stress and declines under relaxed conditions. The Trait-Anxiety Scale for Children (STAIC-T) asks the subjects to describe how they generally feel and measures relatively stable individual differences in anxiety proneness. The total score ranges from 20 to 60 for the 20 questions of each scale, and a total score of 49 is considered as the cutoff value for severe anxiety symptoms in the Korean version [45].

\section{Genotyping}

Genomic DNA was extracted from whole blood lymphocytes using a G-DEXTM II Genomic DNA Extraction Kit (Intron, Korea). The detection of a single nucleotide polymorphism was based on an analysis of primer extension products generated from previously amplified genomic DNA using a chip-based matrix-assisted laser desorption/ ionization time-of-flight (MALDI-TOF) mass spectrometry platform (Sequenom, California, USA). Primers in the PCR and homogeneous Mass Extend (hME) reactions were designed using Assay Designer 3.1 (Sequenom) (5'-ACG TTG GAT GCG TCA TCG TGG AAG ACA TAG and 5'ACG TTG GAT GAC GTT CAG GTG ACA GCA TTC for the rs8049651 polymorphism in GRIN2A, 5'-ACG TTG GAT GTG GAG ATT TGG TGG AAT GAC and $5^{\prime}-$ ACG TTG GAT GTG GAG ATT TGG TGG AAT GAC for the rs2284411 polymorphism in GRIN2B, and $5^{\prime}$-ACG TTG GAT GTG TGA TAC ACA GCT AAG CAG and $5^{\prime}$ ACG TTG GAT GTG AAC CCA AGA CTT CTC ACC for the rs3792452 polymorphism in GRM7).

\section{Statistical analysis}

All data analyses were performed using the Statistical Package for Social Sciences (Version 19.0 for Windows; SPSS, Inc., Chicago, IL, USA). For all data from 202 patients with ADHD and 159 controls, allele frequencies were calculated, and the occurrence of Hardy-Weinberg equilibrium was established by way of goodness-of-fit $x^{2}$ tests. Genotype distribution for each polymorphism was in agreement with the expected values of the HardyWeinberg equilibrium $(p>0.05)$. A family-based study was performed to assess genetic association by transmission disequilibrium test (TDT) statistics.

Subjects with ADHD were divided into genotype groups on the basis of their GRIN2A rs8049651, GRIN2B rs2284411, or GRM7 rs37952452 polymorphism. Due to the small number of individuals having two rare alleles, subjects were dichotomized according to whether they possessed the rare A allele (recessive model). Group differences in the continuous clinical variables were examined using an independent two sample t-test. Between-group comparisons with categorical data were assessed using the $\chi^{2}$ test or Fisher's exact test. The significance level was set at $\mathrm{p}=0.05$ (two-tailed). 


\section{Results}

The case-control analysis included 202 ADHD subjects with a mean age of $9.0+/-2.5$ years and 159 controls with a mean age of $9.0+/-2.7$ years. The mean ages of the two groups were not significantly different $(\mathrm{p}=0.924)$. However, the gender distribution of the two groups differed significantly, as 174 ADHD subjects $(86.1 \%)$ and 111 controls $(69.8 \%)$ were boys $\left(\chi^{2}=14.67, \mathrm{p}<0.001\right)$. Oppositional defiant disorder was the most common (14.4\%) comorbid diagnosis, followed by anxiety disorder (6.5\%), enuresis (5.5\%), and depressive disorder (3.5\%) (Table 1). All participants were ethnically Korean. The family-based analysis included 149 trios consisting of an affected subject and his or her biological father and mother.

The genotype distribution of the three SNPs did not deviate from expectation based on the Hardy-Weinberg equilibrium ( $p>0.05)$. There were no significant differences in the genotype or allele frequencies of the GRIN2A rs8049651, GRIN2B rs2284411, or GRM7 rs37952452 polymorphisms between the ADHD and control groups (Table 2). For 148 ADHD trios, the TDT analysis also showed no preferential transmission of the GRIN2A rs8049651 or GRIN2B rs2284411 polymorphisms. However, the TDT analysis of the GRM7 rs3792452 polymorphism showed biased transmission of the $\mathrm{G}$ allele $(\mathrm{x} 2=4.67, \mathrm{p}=0.031)$ (Table 3$)$.

Table 4 shows the result of the CPT in the ADHD probands according to the genotype at GRM7 rs37952452. A total of 185 ADHD subjects without missing data were included in the analysis. We found no significant differences between excluded $(n=16)$ and included $(n=185)$ subjects with regard to demographic

Table 1 Demographic and clinical characteristics of ADHD subjects and controls

\begin{tabular}{lcc}
\hline & ADHD $(\mathbf{n}=\mathbf{2 0 2})$ & Controls $(\mathbf{n}=\mathbf{1 5 9})$ \\
\hline Age (years), mean \pm SD & $9.0 \pm 2.5$ & $9.0 \pm 2.7$ \\
\hline Sex (males/females) & $174 / 28$ & $111 / 48$ \\
\hline QQ, mean \pm SD & $106.1 \pm 14.7$ & \\
\hline ADHD subtype, \% & 63.0 \\
\hline Combined & 24.5 \\
\hline Inattentive & 6.0 \\
\hline Hyperactive-impulsive & 6.5 \\
\hline Not otherwise specified & \\
\hline Comorbid disorder, \% & 14.4 \\
\hline Oppositional defiant disorder & 1.5 \\
\hline Conduct disorder & 3.5 \\
\hline Depressive disorder & 6.5 \\
\hline Anxiety disorder & 5.5 \\
\hline Enuresis & \\
\hline Abbrevation: & \\
\hline
\end{tabular}

Abbreviations: $A D H D$ attention-deficit hyperactivity disorder, $I Q$ intellectual quotient.
Table 2 Comparison of the genotype and allele frequencies of GRIN2A, GRIN2B, and GRM7 polymorphisms between ADHD probands and controls \begin{tabular}{cccccc}
\hline $\begin{array}{c}\text { ADHD } \\
(n=202)\end{array}$ & $\begin{array}{c}\text { Controls } \\
(n=159)\end{array}$ & X2 & Cohen's w & p \\
\hline$n$ & $\%$ & $n$ & $\%$ & & \\
\hline
\end{tabular} GRIN2A (rs8049651)

\begin{tabular}{lccccccc}
\hline Genotype & & & & & 1.73 & $\mathbf{0 . 0 7}$ & 0.421 \\
\hline GG & 179 & 89.1 & 137 & 88.2 & & & \\
\hline GA & 21 & 10.4 & 22 & 13.8 & & & \\
\hline AA & 1 & 0.5 & 0 & 0 & & & \\
\hline Allele & & & & & 0.46 & $\mathbf{0 . 0 3}$ & 0.499
\end{tabular}

\begin{tabular}{lccccccc}
\hline Allele & & & & & 0.46 & $\mathbf{0 . 0 3}$ & 0.499 \\
\hline $\mathrm{G}$ & 379 & 94.3 & 299 & 93.1 & & & \\
\hline A & 23 & 5.7 & 19 & 6.9 & & & \\
\hline
\end{tabular}

GRIN2B (rs2284411)

\begin{tabular}{llll}
\hline Genotype & 1.52 & $\mathbf{0 . 0 6}$ & 0.469 \\
\hline
\end{tabular}

\begin{tabular}{lcccc}
\hline$C C$ & 128 & 63.7 & 111 & 69.8 \\
\hline$C T$ & 66 & 32.8 & 43 & 27.1 \\
\hline$T$ & 7 & 3.5 & 5 & 3.1 \\
\hline
\end{tabular}

\begin{tabular}{llll}
\hline Allele & 1.16 & $\mathbf{0 . 0 4}$ & 0.281 \\
\hline
\end{tabular}

\begin{tabular}{lcccc}
\hline $\mathrm{C}$ & 322 & 80.1 & 299 & 83.3 \\
\hline $\mathrm{T}$ & 80 & 19.9 & 19 & 16.7 \\
\hline GRM7 (r53792452) & & & &
\end{tabular}

GRM7 (rs3792452)

\begin{tabular}{lccccccc}
\hline Genotype & & & & & 1.62 & $\mathbf{0 . 0 7}$ & 0.444 \\
\hline GG & 174 & 86.6 & 140 & 88.1 & & & \\
\hline GA & 25 & 12.4 & 19 & 11.9 & & & \\
\hline AA & 2 & 1 & 0 & 0 & & & \\
\hline Allele & & & & & 0.42 & $\mathbf{0 . 0 2}$ & 0.551 \\
\hline G & 373 & 92.8 & 299 & 94 & & & \\
\hline A & 29 & 7.2 & 19 & 6 & & & \\
\hline
\end{tabular}

and clinical characteristics. There were no significant differences in age, gender, IQ, ARS scores, ADHD subtypes, or comorbidities between ADHD probands with the GG genotype and the other genotypes at GRM7 rs3792452. The subjects who were homozygous for the G allele (GG genotype) in the GRM7 rs37952452 polymorphism had higher mean T-scores for omission errors

Table 3 Transmission disequilibrium test results for the GRM7 rs37952452 polymorphism

\begin{tabular}{lccccc}
\hline & $\begin{array}{c}\text { Over-transmitted } \\
\text { allele }\end{array}$ & T/NT & $\begin{array}{c}\mathbf{x}^{\mathbf{2}} \\
(\mathbf{d f}=\mathbf{1})\end{array}$ & Cohen's w & $\mathbf{p}$ \\
\hline $\begin{array}{l}\text { GRIN2A } \\
\text { (rs8049651) }\end{array}$ & $G$ & $23 / 16$ & 1.26 & $\mathbf{0 . 0 7}$ & 0.262 \\
\hline $\begin{array}{l}\text { GRIN2B } \\
\text { (rs2284411) }\end{array}$ & G & $58 / 48$ & 0.94 & $\mathbf{0 . 0 6}$ & 0.331 \\
\hline $\begin{array}{l}\text { GRM7 } \\
\text { (rs3792452) }\end{array}$ & G & 28/14 & 4.67 & $\mathbf{0 . 1 3}$ & 0.031 \\
\hline
\end{tabular}

Comparisons were assessed using McNemar's $x^{2}$ test; Number of trios = 149 . 
Table 4 Comparison of the CPT results according to the genotypes of the GRM7 rs37952452 polymorphism in ADHD probands

\begin{tabular}{lccccc}
\hline & $\begin{array}{c}\text { G/G } \\
(\mathbf{n = 1 6 1 )}\end{array}$ & $\begin{array}{c}\text { G/A + AA } \\
\mathbf{( n = 2 4 )}\end{array}$ & t & Cohen's d & p \\
& Mean (SD) & Mean(SD) & & & \\
\hline Omission errors & $82.2(40.9)$ & $62.8(23.3)$ & 3.38 & $\mathbf{0 . 5 8}$ & $0.001^{*}$ \\
\hline Commission errors & $85.0(37.6)$ & $80.8(32.9)$ & 0.51 & $\mathbf{0 . 7 7}$ & 0.608 \\
\hline Response time & $52.7(15.6)$ & $49.0(13.0)$ & 1.11 & $\mathbf{1 . 0 4}$ & 0.269 \\
\hline $\begin{array}{l}\text { Response time } \\
\text { variability }\end{array}$ & $87.4(47.5)$ & $83.1(37.8)$ & 0.43 & $\mathbf{0 . 1 0}$ & 0.668 \\
\hline
\end{tabular}

Abbreviations: $C P T$ continuous performance test, $A D H D$ attention-deficit hyperactivity disorder.

"Significant after Bonferroni correction (0.05/ number of variables of CPT critical p-value of 0.013).

on the CPT than did those with the GA or AA genotype $(t=3.38, p=0.001)$. For the total sample having no missing data ( $\mathrm{n}=336 ; 185$ ADHD probands and 151 controls), the subjects with the GG genotype in the GRM7 rs37952452 polymorphism also showed higher mean T-scores for omission errors on the CPT than did those with the GA or AA genotype $(t=2.17, p=0.034)$. We found no significant differences with regard to commission errors, response time, or response time variability according to the genotypes of GRM7 rs37952452 polymorphism in both ADHD probands and the total sample.

Table 5 shows the results of the STAIC and CDI in the ADHD probands according to the genotype at GRM7 rs37952452. A total of 169 ADHD subjects without missing data and with no comorbid mood or anxiety disorders were included in this analysis. There were no significant differences in age, gender, IQ, ARS scores, or ADHD subtypes between ADHD probands with the GG genotype and the other genotypes at GRM7 rs3792452. Among the 201 ADHD probands, the frequency of a comorbid anxiety disorder was $11.1 \%$ in the ADHD subjects with the GG genotype and $5.7 \%$ in those with the GA or AA genotype $(\mathrm{X} 2=1.11, \mathrm{p}=0.292)$. The frequency of comorbid depressive disorder was $7.4 \%$ in the ADHD subjects with the GG genotype and $2.3 \%$ in those with the GA or AA genotype (X2 = 2.11, $\mathrm{p}=0.147$ ). Among the 169 ADHD subjects included in the analysis, the

Table 5 Comparisons of the CDI, STAI-T, and STAI-S results according to the genotypes of the GRM7 rs37952452 polymorphism in ADHD probands

\begin{tabular}{lccccc}
\hline & G/G $(\mathbf{n}=\mathbf{1 4 8})$ & $\mathbf{G} / \mathbf{A}+\mathbf{A A}(\mathbf{n}=\mathbf{2 1})$ & $\mathbf{t}$ & Cohen's d & $\mathbf{p}$ \\
\hline & Mean (SD) & Mean(SD) & & & \\
\hline STAI-T & $31.8(10.4)$ & $12.3(11.1)$ & 5.52 & $\mathbf{1 . 8 1}$ & $<0.001$ \\
\hline STAI-S & $31.4(10.3)$ & $21.5(14.2)$ & 2.74 & $\mathbf{0 . 8 0}$ & 0.007 \\
\hline CDI & $14.0(7.2)$ & $10.9(7.2)$ & 1.27 & $\mathbf{0 . 4 3}$ & 0.208
\end{tabular}

Abbreviations: $A D H D$ attention-deficit hyperactivity disorder, $C D /$ Children's Depression Inventory, STAIC-T Trait-Anxiety Inventory for Children, STAIC-S State-Anxiety Inventory for Children.
ADHD subjects who were homozygous for the $\mathrm{G}$ allele in the GRM7 rs37952452 polymorphism had higher STAIC-T $(\mathrm{t}=5.52, \mathrm{p}<0.001)$ and STAIC-S $(\mathrm{t}=2.74, \mathrm{p}=0.007)$ scores than did those with the GA or AA genotype.

No significant associations were found among the results of the CPT, STAIC, or CDI and the GRIN2A rs8049651 or GRIN2B rs2284411 genotypes (data available upon request).

\section{Discussion}

In this study, the case-control and family-based association analyses of the GRIN2A rs8049651 and GRIN2B rs2284411 polymorphisms found no significant association of these two polymorphisms with ADHD in Korean subjects. Previously, Turic et al. [23] reported that the GRIN2A rs8049651 polymorphism was associated with ADHD in a family study, but Adams et al. [21] failed to replicate this positive result. Similarly, Dorval et al. [24] reported that the GRIN2B rs2284411 polymorphism was associated with ADHD symptom severity as well as ADHD diagnosis.

The negative results in our study of these loci that had been previously reported as associated with ADHD could be interpreted in several ways. First, if the GRIN2A rs8049651 and GRIN2B rs2284411 polymorphisms are uncommon disease loci or ones of small effect, then our power to detect a gene would be reduced, and the failure to demonstrate a significant association in our case-control analysis might reflect false negative results stemming from the limited sample size and the resulting lower statistical power. Because susceptibility genes for ADHD are likely to have a small effect size [46], more independent case-control studies with larger sample sizes will be required to ensure sufficient study power to detect small gene effects. Second, there is a possibility that the GRIN2A rs8049651 and GRIN2B rs2284411 polymorphisms might have no involvement in the susceptibility to ADHD, at least in the Korean population. Indeed, ethnic differences may have affected the results. In particular, the allele frequencies for the $G$ allele and for the A allele of the GRIN2A rs8049651 in the ADHD probands of this study were 0.94 and 0.06 , respectively, which were very different from those reported in previous studies $(0.69,0.31$ for the Turic sample, and $0.72,0.28$ for the Adams sample), suggesting that findings from Western populations may not be generalizable to the Korean population.

With regard to the GRM7 rs37952452 polymorphism, this is the first study to report an association between the GRM7 polymorphism and ADHD using case-control and family-based analyses. The biased transmission of the $\mathrm{G}$ allele in the TDT analysis of our ADHD trios suggests a possible role of this allele in the development of ADHD. However, we found no association between the GRM7 rs37952452 polymorphism and ADHD using 
the case-control approach. As reviewed by Bobb et al. [47], a relatively high percentage (46\%) of the 26 genetic studies using the family-based and case-control approaches on the same population and polymorphism found divergent results, indicating that both methods should be used to limit the possibility of type II error. Our positive result in the family-based analysis alongside a negative result in the case-control analysis with regard to the GRM7 rs37952452 polymorphism may be partially explained by the small sample size. The number of patients having a minor allele was only 29 in the ADHD group and 19 in the control group, a disparity which might have negatively impacted statistical precision. Therefore, further case-control association studies with larger sample sizes are necessary. Another potential explanation is that differences in population substructures can affect bias estimates in case-control study designs. However, the Korean population is notably characterized by a relatively high genetic homogeneity. Therefore, stratification bias is unlikely to have affected the result of case-control analyses in our sample. It is also possible that the GRM7 rs37952452 polymorphism might have no involvement in the susceptibility to ADHD, and the positive result in our family-based analysis could be a false positive finding.

In this study, the GRM7 rs37952452 polymorphism was associated with omission errors on the CPT. Numerous studies using neuropsychological tests in individuals with ADHD have found deficits in selective attention [48], and continuous performance tests have been frequently used to evaluate attention deficit in ADHD children [49]. In particular, the omission errors are an indicator of deficits in sustained attention in response to target stimuli. Thus, the results of this study suggest that the GRM7 rs37952452 polymorphism could be more closely linked to the intermediate phenotype of selective attention deficits than to the behavioral phenotype or the disease itself. The intermediate phenotype is used to describe a categorical trait or dimension that usually occurs in an "intermediate" position in the causal chain between genes and disease [50]. Because an intermediate phenotype mediates the relationship between genotype and DSM diagnosis and is more closely connected to genetic functionality, larger magnitudes for genetic effects might be evident and more easily detectable in smaller samples [51]. Furthermore, a relationship between omission error scores and the GRM7 rs37952452 genotype was evident in the total sample (including controls) as well as for ADHD probands, suggesting that this polymorphism might be associated with sub-threshold attention-deficit in the general population.

Although the frequency of a comorbid anxiety disorder did not significantly differ according to the GRM7 rs37952452 genotype, it is notable that the GG genotype of the GRM7 rs37952452 polymorphism was associated with higher state and trait anxiety scores even after excluding the subjects with comorbid anxiety disorders. An association between GRM7 and anxiety has been previously reported. Animal studies, for example, have shown that mGluR7 ablation can cause deficits in fear response [30], and mGluR7 facilitates extinction of aversive memories and controls amygdala plasticity [29]. Elia et al. [52] observed an ADHD proband with a copy number variation in GRM7 gene who also presented with anxiety and suggested that this copy number variation may potentially explain certain comorbidities frequently associated with ADHD. Our results also support the idea that GRM7 rs3795245 polymorphism represents certain phenotypes such as anxious ADHD as well as the ADHD diagnosis itself.

Several limitations of this study should be noted. First, the patient group included all subtypes of ADHD, which might have contributed to clinical heterogeneity. Second, although the genotype distribution was not different according to ADHD subtypes, when we compared the $\mathrm{CPT}, \mathrm{CDI}$, and STAI-C results according to the genotypes, the subtypes might have acted as potential confounders. Third, because of the relatively small sample size, the samples of this study would have limited power to detect genes of small effect. Finally, we genotyped only one specific SNP of GRIN2A, GRIN2B, or GRM7, and this may have been insufficient to fully address the association between these glutamate genes and ADHD.

\section{Conclusions}

These results provide preliminary evidence of an association between the GRM7 rs37952452 polymorphism and selective attention deficit and anxiety found within the Korean ADHD population. Further studies, including a replication of these findings with more SNPs in a larger sample, are warranted to evaluate the association of glutamate genes and complex phenotypes of ADHD.

\section{Abbreviations \\ ADHD: Attention-deficit hyperactivity disorder; NMDA: N-methyl-D - aspartate; NMDAR: N-methyl-D-aspartate receptor; mGluR: Metabotropic glutamate receptor; GRM7: Metabotropic glutamate receptor mGluR7 gene; DSM-IV-TR: Diagnostic and Statistical Manual of Mental Disorders, 4th edition, text revision; ARS: ADHD Rating Scale-IV; CBCL: Child Behavior Checklist; IQ: Intelligent quotient; DISC-IV: Diagnostic Interview Schedule for Children Version-IV; CPT: Computerized continuous performance test; CDI: Children's Depression Inventory; STAIC: State-Trait Anxiety Inventory for Children.}

\section{Competing interests}

None of the authors have any financial interest in the study, or any other competing interest.

\section{Authors' contributions}

SWJ, SCC, JWK, HJY, USC, JWS, and HWK participated in data collection. DYC and SWJ analyzed the data. SWJ prepared the first draft of the report. SCC and MSS supervised the statistical analysis. SP and BNK interpreted the results. SP wrote the final report with input from all the authors. All authors read and approved the final manuscript. 


\section{Acknowledgements}

This study was supported by a grant of the Korean Health Technology R\&D Project, Ministry of Health \& Welfare, Republic of Korea (A111523) and by Basic Science Research Program through the National Research Foundation of Korea (NRF) funded by the Ministry of Education, Science and Technology (2012-0008291).

\section{Author details}

'Department of Child and Adolescent Psychiatry, Seoul National University Hospital, Seoul, Korea. ${ }^{2}$ Department of Psychiatry, Seoul National University Bundang Hospital, Seongnam, Gyeonggi, Korea. ${ }^{3}$ Lab Genomics Clinical Research Institute, Seoul, Korea. ${ }^{4}$ Department of Psychiatry, Kyungpook National University Hospital, Daegu, Korea. ${ }^{5}$ Department of Psychiatry, Chungbuk National University Hospital, Cheongju, Korea. ${ }^{6}$ Department of Psychiatry, Ulsan University College of Medicine, Asan Medical Center, Seoul, Korea.

Received: 11 September 2012 Accepted: 19 December 2012 Published: 7 January 2013

\section{References}

1. Polanczyk G, de Lima MS, Horta BL, Biederman J, Rohde LA: The worldwide prevalence of ADHD: a systematic review and metaregression analysis. Am J Psychiatry 2007, 164:942-948.

2. Franke B, Neale BM, Faraone SV: Genome-wide association studies in ADHD. Hum Genet 2009, 126:13-50.

3. Biederman J, Spencer T: Attention-deficit/hyperactivity disorder (ADHD) as a noradrenergic disorder. Biol Psychiatry 1999, 46:1234-1242.

4. Pliszka SR, McCracken JT, Maas JW: Catecholamines in attention-deficit hyperactivity disorder: current perspectives. J Am Acad Child Adolesc Psychiatry 1996, 35:264-272.

5. Giros B, Jaber M, Jones SR, Wightman RM, Caron MG: Hyperlocomotion and indifference to cocaine and amphetamine in mice lacking the dopamine transporter. Nature 1996, 379:606-612.

6. Jin Z, Zang YF, Zeng YW, Zhang L, Wang YF: Striatal neuronal loss or dysfunction and choline rise in children with attention-deficit hyperactivity disorder: a $1 \mathrm{H}$-magnetic resonance spectroscopy study. Neurosci Lett 2001, 315:45-48.

7. MacMaster FP, Carrey N, Sparkes S, Kusumakar V: Proton spectroscopy in medication-free pediatric attention-deficit/hyperactivity disorder. Biol Psychiatry 2003, 53:184-187.

8. Courvoisie H, Hooper SR, Fine C, Kwock L, Castillo M: Neurometabolic functioning and neuropsychological correlates in children with ADHD-H: preliminary findings. J Neuropsychiatry Clin Neurosci 2004, 16:63-69.

9. Carrey N, MacMaster FP, Fogel J, Sparkes S, Waschbusch D, Sullivan S, Schmidt M: Metabolite changes resulting from treatment in children with ADHD: a 1H-MRS study. Clin Neuropharmacol 2003, 26:218-221.

10. DasBanerjee T, Middleton FA, Berger DF, Lombardo JP, Sagvolden T, Faraone SV: A comparison of molecular alterations in environmental and genetic rat models of ADHD: a pilot study. Am J Med Genet Part B Neuropsychiatric Genet: Int Soc Psychiatr Genet 2008, 147B:1554-1563.

11. Sagvolden T, Johansen EB, Woien G, Walaas SI, Storm-Mathisen J, Bergersen $L H$, Hvalby $O$, Jensen V, Aase H, Russell VA, et al: The spontaneously hypertensive rat model of ADHD-the importance of selecting the appropriate reference strain. Neuropharmacology 2009, 57:619-626.

12. Ozawa S, Kamiya H, Tsuzuki K: Glutamate receptors in the mammalian central nervous system. Prog Neurobiol 1998, 54:581-618.

13. Riedel G, Platt B, Micheau J: Glutamate receptor function in learning and memory. Behav Brain Res 2003, 140:1-47.

14. Nakanishi S: Metabotropic glutamate receptors: synaptic transmission, modulation, and plasticity. Neuron 1994, 13:1031-1037.

15. Pin JP, Duvoisin R: The metabotropic glutamate receptors: structure and functions. Neuropharmacology 1995, 34:1-26.

16. Flor PJ, Van Der Putten H, Ruegg D, Lukic S, Leonhardt T, Bence M, Sansig G, Knopfel T, Kuhn R: A novel splice variant of a metabotropic glutamate receptor, human mGluR7b. Neuropharmacology 1997, 36:153-159.

17. Miyamoto Y, Yamada K, Noda Y, Mori H, Mishina M, Nabeshima T: Hyperfunction of dopaminergic and serotonergic neuronal systems in mice lacking the NMDA receptor epsilon1 subunit. J Neurosci 2001, 21:750-757.
18. Sakimura K, Kutsuwada T, Ito I, Manabe T, Takayama C, Kushiya E, Yagi T, Aizawa S, Inoue $\mathrm{Y}$, Sugiyama $\mathrm{H}$, et al: Reduced hippocampal LTP and spatial learning in mice lacking NMDA receptor epsilon 1 subunit. Nature 1995, 373:151-155.

19. Tang YP, Shimizu E, Dube GR, Rampon C, Kerchner GA, Zhuo M, Liu G, Tsien JZ: Genetic enhancement of learning and memory in mice. Nature 1999, 401:63-69.

20. Kutsuwada T, Sakimura K, Manabe T, Takayama C, Katakura N, Kushiya E, Natsume R, Watanabe M, Inoue Y, Yagi T, et al: Impairment of suckling response, trigeminal neuronal pattern formation, and hippocampal LTD in NMDA receptor epsilon 2 subunit mutant mice. Neuron 1996, 16:333-344.

21. Adams J, Crosbie J, Wigg K, Ickowicz A, Pathare T, Roberts W, Malone M, Schachar R, Tannock R, Kennedy JL, Barr CL: Glutamate receptor, ionotropic, N-methyl D-aspartate 2A (GRIN2A) gene as a positional candidate for attention-deficit/hyperactivity disorder in the 16p13 region. Mol Psychiatry 2004, 9:494-499.

22. Smalley SL, Kustanovich V, Minassian SL, Stone JL, Ogdie MN, McGough JJ, McCracken JT, MacPhie IL, Francks C, Fisher SE, et al: Genetic linkage of attention-deficit/hyperactivity disorder on chromosome 16p13, in a region implicated in autism. Am J Hum Genet 2002, 71:959-963.

23. Turic D, Langley K, Mills S, Stephens M, Lawson D, Govan C, Williams N, Van Den Bree M, Craddock N, Kent L, et al: Follow-up of genetic linkage findings on chromosome 16p13: evidence of association of N-methyl-D aspartate glutamate receptor $2 \mathrm{~A}$ gene polymorphism with $\mathrm{ADHD}$. Mol Psychiatry 2004, 9:169-173.

24. Dorval KM, Wigg KG, Crosbie J, Tannock R, Kennedy JL, Ickowicz A, Pathare T, Malone M, Schachar R, Barr CL: Association of the glutamate receptor subunit gene GRIN2B with attention-deficit/hyperactivity disorder. Genes Brain Behav 2007, 6:444-452.

25. Kinoshita A, Shigemoto R, Ohishi $H$, van der Putten $H$, Mizuno N: Immunohistochemical localization of metabotropic glutamate receptors, mGluR7a and mGluR7b, in the central nervous system of the adult rat and mouse: a light and electron microscopic study. J Comp Neurol 1998, 393:332-352.

26. Kosinski CM, Risso Bradley S, Conn PJ, Levey Al, Landwehrmeyer GB, Penney $J B$ Jr, Young AB, Standaert DG: Localization of metabotropic glutamate receptor $7 \mathrm{mRNA}$ and mGluR7a protein in the rat basal ganglia. J Comp Neurol 1999, 415:266-284.

27. Callaerts-Vegh Z, Beckers T, Ball SM, Baeyens F, Callaerts PF, Cryan JF, Molnar E, D'Hooge R: Concomitant deficits in working memory and fear extinction are functionally dissociated from reduced anxiety in metabotropic glutamate receptor 7-deficient mice. J Neurosci 2006, 26:6573-6582

28. Cryan JF, Kelly PH, Neijt HC, Sansig G, Flor PJ, van Der Putten H: Antidepressant and anxiolytic-like effects in mice lacking the group III metabotropic glutamate receptor mGluR7. Eur J Neurosci 2003, 17:2409-2417.

29. Fendt M, Schmid S, Thakker DR, Jacobson LH, Yamamoto R, Mitsukawa K, Maier R, Natt F, Husken D, Kelly PH, et al: mGluR7 facilitates extinction of aversive memories and controls amygdala plasticity. Mol Psychiatry 2008, 13:970-979.

30. Masugi M, Yokoi M, Shigemoto R, Muguruma K, Watanabe $Y$, Sansig G, van der Putten H, Nakanishi S: Metabotropic glutamate receptor subtype 7 ablation causes deficit in fear response and conditioned taste aversion. J Neurosci 1999, 19:955-963.

31. Mick E, Neale B, Middleton FA, McGough JJ, Faraone SV: Genome-wide association study of response to methylphenidate in 187 children with attention-deficit/hyperactivity disorder. Am J Med Genet Part B, Neuropsychiatric Genet: Int Soc Psychiatr Genet 2008, 147B:1412-1418.

32. Kim JW: Association study and population admixture. Human neurobehavioral genetics in the 21st century. Seoul: Korean Society of Biological Psychiatry; 2003.

33. So YK, Noh JS, Kim YS, Ko SG, Koh YJ: The reliability and validity of Korean parent and teacher ADHD rating scale. J Korean Neuropsychiatr Assoc 2002, 41:283-289.

34. Oh KJ, Lee H, Hong KE, Ha EH: K-CBCL. Seoul, Korea: Chung Ang Aptitude Publishing Co; 1997.

35. Park KS, Yoon JY, Park HJ, Park HJ, Kwon KU: Development of KEDI-WISC, individual intelligence test for Korean children. Seoul: Korean Educational Development Institute; 1996.

36. Shaffer D, Fisher P, Lucas CP, Dulcan MK, Schwab-Stone ME: NIMH Diagnostic Interview Schedule for Children Version IV (NIMH DISC-IV): 
description, differences from previous versions, and reliability of some common diagnoses. J Am Acad Child Adolesc Psychiatry 2000, 39:28-38.

37. Cho SC, Kim BN, Kim JW, Kim HW, Choi HJ, Jung SW, Yang YH DSC, Go BJ, Kim BS, et al: The reliability and validity of diagnostic interview schedule for children version IV-Korean version (DISC-IV). J Korean Acad Child Adolesc Psychiatry 2006, 18:138-144.

38. Kaufman J, Birmaher B, Brent D, Rao U, Flynn C, Moreci P, Williamson D, Ryan N: Schedule for affective disorders and schizophrenia for schoolage children-present and lifetime version (K-SADS-PL): initial reliability and validity data. J Am Acad Child Adolesc Psychiatry 1997, 36:980-988.

39. Kim YS, Cheon KA, Kim BN, Chang SA, Yoo HJ, Kim JW, Cho SC, Seo DH, Bae $\mathrm{MO}$, So YK, et al: The reliability and validity of kiddie-schedule for affective disorders and schizophrenia-present and lifetime versionKorean version (K-SADS-PL-K). Yonsei Med J 2004, 45:81-89.

40. Greenberg LM, Waldman ID: Developmental normative data on the test of variables of attention (T.O.V.A.). J Child Psychol Psychiatry 1993, 34:1019-1030.

41. Shin MS, Cho S, Chun SY, Hong KE: A study of the development and standardization of ADHD Diagnostic System. Korean J Child \& Adol Psychiatr 2000, 11:91-99.

42. Kovacs M: The Children's Depression, Inventory (CDI). Psychopharmacol Bull 1985, 21:995-998.

43. Cho SC, Lee YS: Development of the Korean version of children's depression inventory. J Korean Neuropsychiatr Assoc 1990, 29:943-956.

44. Spielberger CD: Manual for the State-Trait Anxiety Inventory for Children. Palo Alto, CA: Consulting Psychological Press; 1972.

45. Cho SC, Choi JS: Development of the Korean version of state-trait anxiety inventory for children. Seoul Rev Psychiatry 1989, 14:150-157.

46. Smalley SL: Genetic influences in childhood-onset psychiatric disorders: autism and attention-deficit/hyperactivity disorder. Am J Hum Genet 1997, 60:1276-1282

47. Bobb AJ, Addington AM, Sidransky E, Gornick MC, Lerch JP, Greenstein DK, Clasen LS, Sharp WS, Inoff-Germain G, Wavrant-De Vrieze F, et al: Support for association between ADHD and two candidate genes: NET1 and DRD1. Am J Med Genet Part B, Neuropsychiatric Genet: Int Soc Psychiatr Genet 2005, 134B:67-72.

48. Castellanos FX, Tannock R: Neuroscience of attention-deficit/hyperactivity disorder: the search for endophenotypes. Nat Rev Neurosci 2002, 3:617-628.

49. Oades RD: Differential measures of 'sustained attention' in children with attention-deficit/hyperactivity or tic disorders: relations to monoamine metabolism. Psychiatry Res 2000, 93:165-178.

50. Szatmari P, Maziade M, Zwaigenbaum L, Merette C, Roy MA, Joober R, Palmour R: Informative phenotypes for genetic studies of psychiatric disorders. Am J Med Genet Part B, Neuropsychiatric Genet: Int SocPsychiatr Genet 2007, 144B:581-588.

51. Flint J, Munafo MR: The endophenotype concept in psychiatric genetics. Psychol Med 2007, 37:163-180.

52. Elia J, Glessner JT, Wang K, Takahashi N, Shtir CJ, Hadley D, Sleiman PM, Zhang H, Kim CE, Robison R, et al: Genome-wide copy number variation study associates metabotropic glutamate receptor gene networks with attention deficit hyperactivity disorder. Nat Genet 2012, 44:78-84.

doi:10.1186/1744-9081-9-1

Cite this article as: Park et al:: Association between the GRM7 rs3792452 polymorphism and attention deficit hyperacitiveity disorder in a Korean sample. Behavioral and Brain Functions 2013 9:1.

\section{Submit your next manuscript to BioMed Central and take full advantage of:}

- Convenient online submission

- Thorough peer review

- No space constraints or color figure charges

- Immediate publication on acceptance

- Inclusion in PubMed, CAS, Scopus and Google Scholar

- Research which is freely available for redistribution

Submit your manuscript at www.biomedcentral.com/submit 